
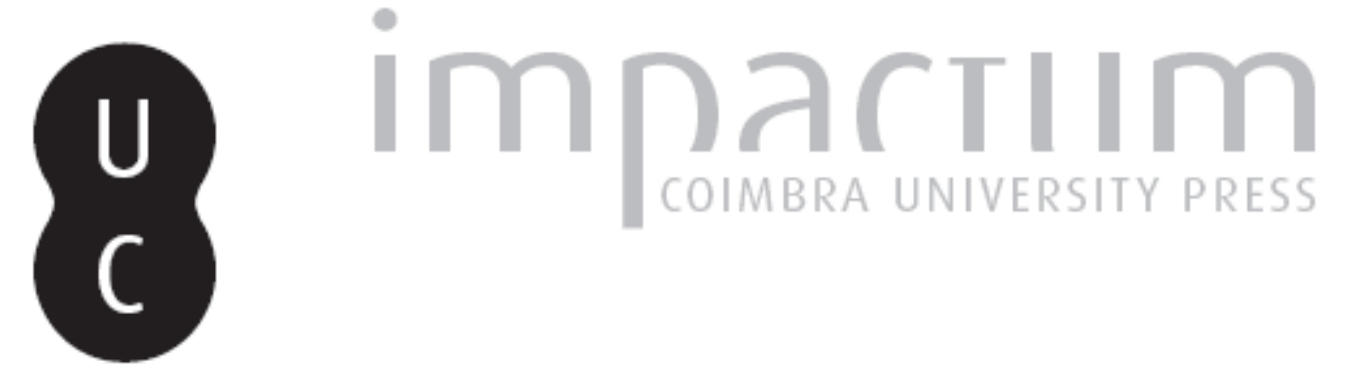

\title{
[Recensão a] Eça de Queirós, La Corrispondenza di Fradique Mendes. Memorie e note, a cura di Roberto Vecchi e Vincenzo Russo
}

Autor(es): $\quad$ Simões, Manuel G.

Publicado por: Imprensa da Universidade de Coimbra

URL

persistente:

URI:http://hdl.handle.net/10316.2/42586

DOI:

DOI:https://doi.org/10.14195/0870-8584_4_15

Accessed : $\quad$ 26-Apr-2023 11:43:02

A navegação consulta e descarregamento dos títulos inseridos nas Bibliotecas Digitais UC Digitalis, UC Pombalina e UC Impactum, pressupõem a aceitação plena e sem reservas dos Termos e Condições de Uso destas Bibliotecas Digitais, disponíveis em https://digitalis.uc.pt/pt-pt/termos.

Conforme exposto nos referidos Termos e Condições de Uso, o descarregamento de títulos de acesso restrito requer uma licença válida de autorização devendo o utilizador aceder ao(s) documento(s) a partir de um endereço de IP da instituição detentora da supramencionada licença.

Ao utilizador é apenas permitido o descarregamento para uso pessoal, pelo que o emprego do(s) título(s) descarregado(s) para outro fim, designadamente comercial, carece de autorização do respetivo autor ou editor da obra.

Na medida em que todas as obras da UC Digitalis se encontram protegidas pelo Código do Direito de Autor e Direitos Conexos e demais legislação aplicável, toda a cópia, parcial ou total, deste documento, nos casos em que é legalmente admitida, deverá conter ou fazer-se acompanhar por este aviso.

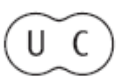




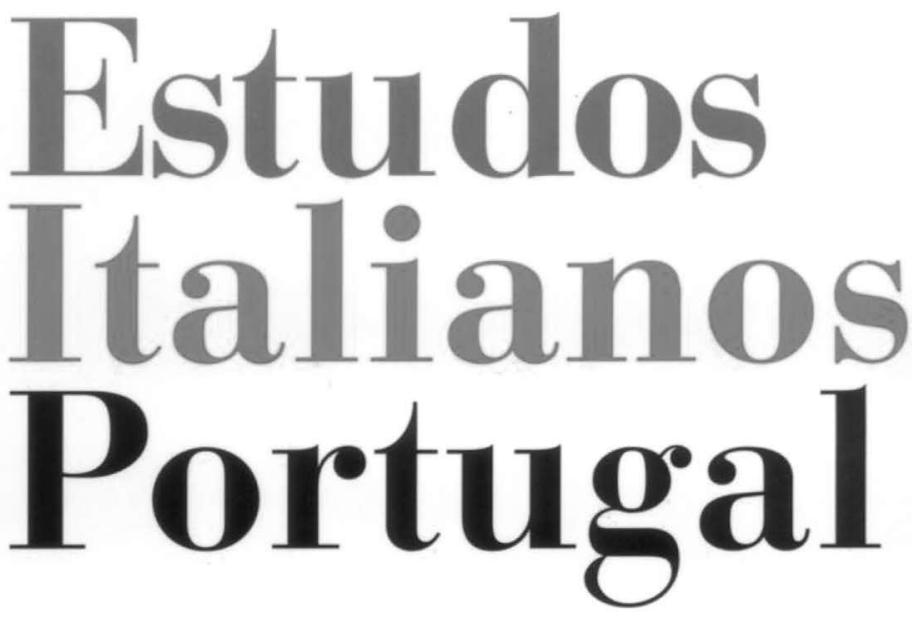

Instituto

Italiano

de Cultura

de Lisboa

Nova Série

$\mathbf{N}^{\mathbf{0}} 4$.

2009 
Eça de Queirós, La Corrispondenza di Fradique Mendes. Memorie e note, a cura di Roberto Vecchi e Vincenzo Russo, Reggio Emilia, Diabasis, 2009, pp. 215

Ainda inédito em Itália, não obstante as inúmeras traduções da obra queirosiana, o presente volume colmata uma lacuna clamorosa e apresenta-se como edição extremamente cuidada do controverso romance de Eça de Queirós que tem como protagonista o não menos controverso "poeta satânico" Carlos Fradique Mendes. Como se sabe, este resulta da criação heteronímica da responsabilidade do próprio Eça, de Antero de Quental e de Jaime Batalha Reis, estabelecendo o romance traços distintivos, mesmo ao nível da biografia, que caracterizam simultaneamente o poeta e os três criadores, embora seja o biógrafo de Fradique quem institui uma maior afinidade com o biografado através de não poucas semelhanças de que se destacam o cosmopolitismo, o dandysmo e especialmente a crítica ao quotidiano de Lisboa, considerada por Fradique (e por Eça) uma cidade "afadistada e provinciana". De facto, a Eça de Queirós se pode aplicar a síntese que Oliveira Martins "elaborou" sobre Fradique em carta de Novembro de 1877, "endereçada" ao autor de Os Maias: "singolare mescolanza di istinti romanzeschi e di esatta ragione, di fantasia e di geometria" (IV, p.62). Seja como for, esta figura fantasmática da literatura portuguesa foi concebida precisamente como figura da modernidade que se pretendia introduzir em Portugal e cuja 
biografia aponta para muitos problemas de uma estética que deveria dar consistência à nova literatura que, como é sabido, teve origem no manifesto de Coimbra de 1865, tomou forma com as Conferências Democráticas de 1871 e acabou por ter vida efémera.

Sobre o significado da obra e estabelecendo uma estreita ligação entre a proposta fradiquiana e a pluralidade de discursos, sobretudo do último Eça de Queirós, é de salientar o excelente ensaio introdutório de Roberto Vecchi, que ao Autor tem dedicado alguns estudos sem dúvida iluminantes. Nele se confirma o estatuto de narrador único, tal como se configura em $A$ Correspondência de Fradique Mendes, o qual, colocando no centro do discurso episódios da vida de um outro, na verdade conduz o fio da narrativa para si próprio no sentido da figura que assume a crise, constituindo-se Fradique como duplo do narrador, isto é, "tra personaggio e narratore si istituisce un flusso dialogico intenso tanto che l'uno esiste in funzione dell'altro, come nell'aporia del testimone" (p. 15). Perspicaz, sem dúvida, a análise de Roberto
Vecchi e a conclusão de que "Fradique in sostanza siamo 'noi', come peraltro avviene in molti degli scritti ultimi di Eça, laddove l'identità narrativa di un personaggio si trasforma per allegoria in istanza colletiva, quando non in narrativa di nazione" (p. 19). A tradução, de Vincenzo Russo, é fluente, sóbria mas aprazível, e denuncia a grande atenção à floresta de autores citados no romance, para acentuar a erudição e o cosmopolitismo, cujos nomes foram normalizados segundo a prática corrente. E o tradutor é também autor da nota final biobibliográfica na qual se reconstroem as peripécias que conduzem ao Autor do livro e à criação do "poeta satânico" pensando na "riqueza imensa do moderno movimento de ideias", como referirá Jaime Batalha Reis; e se recupera a história editorial do livro, cuja génese remonta aos anos que decorrem de 1885, ano em que Eça revela a intenção de publicar a obra, até 1900, data da morte do Autor, em que apenas uma parte se encontrava tipograficamente composta. Estes dois aspectos mereceram de Vincenzo Russo uma paciente e rigorosa investigação, unindo e iluminando 
os fios dos diversos fragmentos de uma biografia imaginária que, por sua vez, engloba personagens e ideologias que formaram a vanguarda portuguesa na segunda metade do século XIX. MANUEL G. SIMÕES

Traduzioni, imitazioni, scambi tra Italia e Portogallo nei secoli (Atti del primo Colloquio internazionale, Pisa, 15-16 ottobre 2004), a cura di Monica Lupetti, Firenze, Leo S. Olschki Editore, 2008, 171 pp. +15 pp. extra-texto.

O título da obra, Traduzioni, imitazioni, scambi tra Italia e Portogallo nei secoli (Atti del primo Colloquio internazionale, Pisa, 15-16 ottobre 2004), desperta interesse, prometendo sob um tema agregador matéria vária: este é - advertem Davide Conrieri e Valeria Tocco, que assinam as páginas proemiais - mais um fruto do trabalho que, desde 2001, o empenho conjunto de duas instituições de prestígio (a Scuola Normale Superiore di Pisa e a Università di Pisa) vem permitindo desenvolver sobre as relações literárias entre a Itália e a Península Ibérica. No volume em apreço - sublinham ainda Davide Conrieri e
Valeria Tocco - tem lugar, simultaneamente, uma restrição e uma expansão dessa pesquisa: restrição, porque se privilegia Portugal; expansão porque, além dos períodos renascentista e barroco, a atenção prestada a nexos culturais luso-italianos alastra a épocas diversas, atingindo a contemporaneidade.

Se o breve depoimento de Adelina Aletti ("Tradurre di dentro", pp. 21-23) evidencia a força dos afectos e das circunstâncias na sua carreira de tradutora de autores portugueses e brasileiros, o ensaio de Luciana Stegagno Picchio ("Tradurre Petrarca: la traduzione portoghese delle Rime di Vasco Graça Moura, con un breve excursus sul problema del tradurre", pp. 1-20) torna clara a complexidade tanto do labor da tradução como dos resultados a que conduz. De facto, ao observar e comentar a versão dos $R e$ rum Vulgarium Fragmenta (ou Canzoniere, ou Rime...) realizada por Vasco Graça Moura, Luciana Stegagno Picchio prova a importância que no acto de trasladar assume, mais do que a compreensão, a interpretação dos textos e a consciência da poética de que são parte: "La traduzione non è 